\title{
CORRIGENDUM
}

\section{Pit- and trench-forming osteoclasts: a distinction that matters}

Ditte MH Merrild, Dinisha C Pirapaharan, Christina M Andreasen, Per Kjærsgaard-Andersen, Anaïs MJ Mùller, Ming Ding, Jean-Marie Delaissé and Kent Sùe

Bone Research (2016) 4, 16006; doi:10.1038/boneres.2016.6; published online: 22 March 2016

Correction to: Bone Research (2015) 3, 15032. doi:10.1038/ boneres.2015.32

Since the online publication of the above article, it was noticed that the symbol indicating the statistical significance was missed in Figure 4a. The correct figure is shown here. The corrected article appears online together with this corrigendum.

The journal staff would like to apologise for this error.
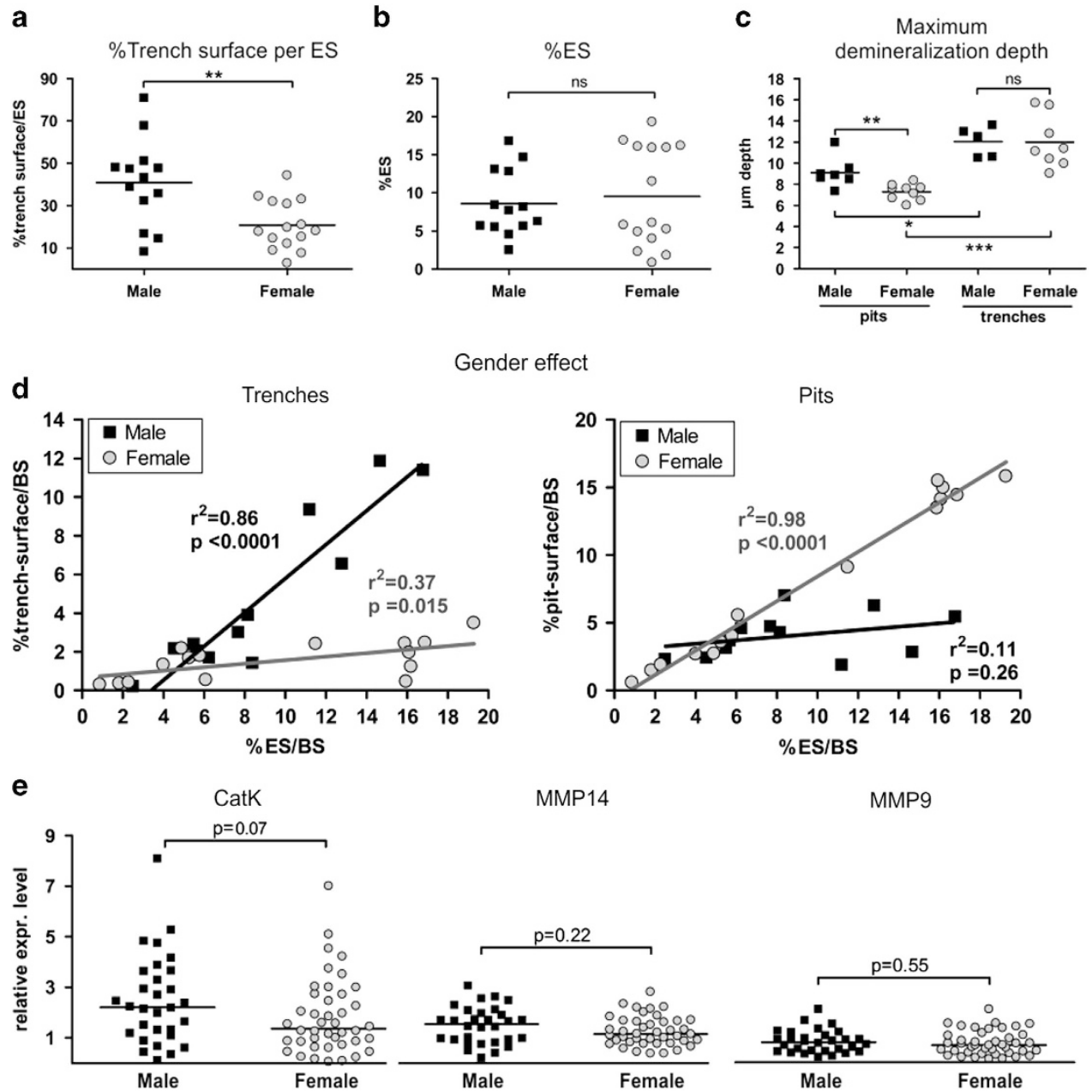

MMP14

MMP9

Figure 4 . 